\title{
Novel Inhaled Pan-JAK Inhibitor, LAS194046, Reduces Allergen- Induced Airway Inflammation, Late Asthmatic Response, and pSTAT Activation in Brown Norway Rats
}

\author{
Marta Calbet, Isabel Ramis, Elena Calama, Cristina Carreño, Stephane Paris, \\ Monica Maldonado, Adelina Orellana, Elena Calaf, Montse Pauta, Jorge De Alba, \\ Jordi Bach, and Montserrat Miralpeix \\ Almirall R\&D Center, Sant Feliu de Llobregat, Barcelona, Spain \\ Received January 3, 2019; accepted May 8, 2019
}

\section{ABSTRACT}

The Janus-activated kinase (JAK) family together with signal transducer and activator of transcription (STAT) signaling pathway has a key role in regulating the expression and function of many inflammatory cytokines. This has led to the discovery of JAK inhibitors for the treatment of inflammatory diseases, some of them already in the market. Considering the adverse effects associated with JAK inhibition by oral route, we wanted to explore whether JAK inhibition by inhaled route is enough to inhibit airway inflammation. The aim of this study was to characterize the enzymatic and cellular potency and the selectivity of LAS194046, a novel JAK inhibitor, compared with the reference compounds ruxolitinib and tofacitinib. The efficacy of this new JAK inhibitor is described in a model of ovalbumin
\end{abstract}

(OVA)-induced airway inflammation in Brown Norway rats by inhaled administration. As potential markers of target engagement, we assessed the effect of LAS194046 on the STAT activation state. LAS194046 is a selective inhaled pan-JAK inhibitor that reduces allergen-induced airway inflammation, late asthmatic response, and phosphor-STAT activation in the rat OVA model. Our results show that topical inhibition of JAK in the lung, without relevant systemic exposure, is sufficient to reduce lung inflammation and improve lung function in a rat asthma model. In summary, JAK-STAT pathway inhibition by inhaled route constitutes a promising therapeutic option for lung inflammatory diseases.

\section{Introduction}

The Janus-activated kinase (JAK) family of cytoplasmic tyrosine kinases comprises four isoforms, JAK1, JAK2, JAK3, and Tyrosine kinase 2 (TYK2). JAKs have a key role in cytokine function, transducing cytokine-mediated signals through the association and activation of signal transducers and activators of transcription factor (STAT) proteins (Yamaoka et al., 2004). Seven different STAT members (STAT1, STAT2, STAT3, STAT4, STAT5A, STAT5B, and STAT6) have been described (Shuai, 2006). Upon cytokine

This work was partially published in abstract form at the European Respiratory Society meeting in 2014 in Munich: Ramis I, Carreño C, Orellana A, Maldonado M, Bach J, and Miralpeix M (2014) In vitro profile of the new inhaled pan-JAK inhibitor LAS194046. Eur Respir $J$ 44:P1508. Ramis I, Calama E, Domènech A, Carreño $\mathrm{C}$, Calaf E, Cordoba M, Alberti J, De Alba J, Bach J, Prats N, et al. (2014) New inhaled JAK inhibitor LAS194046 inhibits allergen-induced airway inflammation in Brown Norway rats. Eur Respir J 44:3412.

Conflict of interest: All authors were employees of Almirall when this study was performed.

This work was supported by Almirall with the partial support of the Center for Technological and Industrial Development of Spain [Ref. IDI-20130948].

https://doi.org/10.1124/jpet.119.256263. binding, receptor intracellular domains reorient and physically contact the JAK proteins to receive the phosphorylation modification. This process creates binding sites for the Src homology 2 domains of the STATs, thereby recruiting and phosphorylating the corresponding STATs, which dimerize and move to the nucleus to activate gene expression involved in inflammatory responses (Murray, 2007). Different interactions of JAK isoforms are used by many cytokine-receptor complexes. The receptors for cytokines such as interleukin (IL)-2, IL-4, IL-7, IL-9, IL-15, and IL-21 preferentially interact with JAK3 and JAK1 and are primarily associated with adaptive immunity (Suzuki et al., 2000). Relevant proinflammatory cytokines associated with innate immune response such as type II interferon (IFN) $\gamma$ and IL-6 receptor interact in both cases with JAK1 and JAK2, but also with TYK2 in the case of IL-6 (O'Shea and Plenge, 2012). JAK2 associates with the IL-3 and IL-5 cytokine receptors, but also in the receptors of granulocyte-macrophage colony-stimulating factor (GM-CSF), erythropoietin, and thrombopoietin, indicating that JAK2 plays a role not only in the signaling of proinflammatory cytokines, but also in processes of hematopoiesis (Park et al., 2013). JAK2 as well as TYK2 interacts with IL-12 and IL-23

ABBREVIATIONS: BALF, bronchoalveolar lavage fluid; COPD, chronic obstructive pulmonary disease; GM-CSF, granulocyte-macrophage colonystimulating factor; IFN, interferon; IL, interleukin; JAK, Janus-activated kinase; LAR, late asthmatic response; OVA, ovalbumin; PBMC, peripheral blood mononuclear cell; PK, pharmacokinetic; PSTAT, phosphor-STAT; STAT, signal transducer and activator of transcription; Th, T helper; TYK2, Tyrosine kinase 2. 
cytokine receptors that are associated with $\mathrm{T}$ helper (Th)1 and Th17 differentiation, respectively (Minegishi et al., 2006). Both JAK2 and TYK2 together with JAK1 associate with IL-13 receptor related with Th2 phenotype after recruitment of STAT6; in fact, polymorphisms of the latter are associated with asthma, atopy, and increased levels of IgE (O'Shea et al., 2015), showing as a whole the impact of the JAK-STAT pathway on human disease and potential for therapeutic intervention.

JAK inhibitors (Jakinibs) such as ruxolitinib (Jakafi; Incyte/Novartis), tofacitinib (Xeljanz; Pfizer), and baricitinib (Olumiant; Incyte/Eli Lilly) have been approved by the Food and Drug Administration. Ruxolitinib is a pan-JAK inhibitor effective in the treatment of myeloproliferative neoplasms (Geyer and Mesa, 2014) that is currently being evaluated in clinical studies (clinicaltrials.gov) for different malignancies and inflammatory diseases such as alopecia areata (MackayWiggan et al., 2016), vitiligo (Rothstein et al., 2017), and psoriasis (Hsu and Armstrong, 2014). Tofacitinib is also a panJAK inhibitor (Flanagan et al., 2010), with less affinity for JAK2 than ruxolitinib, that has been approved for the treatment of rheumatoid arthritis in patients who have an inadequate response to methotrexate (Anonymous, 2012). Other indications such as psoriasis (Ports et al., 2013), ulcerative colitis (Sandborn et al., 2012), and Crohn's disease (Vuitton et al., 2013) are under clinical investigation. Furthermore, other JAK inhibitors are also under development for oncology indications, in which JAK activation and signaling play a relevant role (Dymock et al., 2014). More recently, in February 2017, baricitinib was approved for use in the European Union as a second-line therapy for moderate to severe active rheumatoid arthritis in adults, either alone or in combination with methotrexate (European Medicines Agency, 2017), with other indications such as lupus erythematosus and atopic dermatitis under clinical investigation (Wallace et al., 2018; Guttman-Yassky et al., 2019).

In the respiratory area, JAK inhibitors have demonstrated promising results in in vitro studies with cells isolated from asthma patients showing reduction of cytokine levels and an additive effect in combination with corticosteroids (Southworth et al., 2016). In in vivo models of airway inflammation, a reduction in lung inflammation has been reported (Kudlacz et al., 2008; Ashino et al., 2014; Calama et al., 2017), suggesting that JAK inhibition is a potential therapeutic target for the treatment of respiratory inflammatory diseases such as asthma and chronic obstructive pulmonary disease (COPD). Inhaled JAK inhibitors could be a relevant option to avoid potential systemic adverse effects associated to oral JAK inhibitors such as infections, intestinal perforations, malignancies, and changes in hematologic and biochemical parameters, including lymphopenia, neutropenia, and increased levels of liver transaminases and lipids (Winthrop, 2017). A pan-JAK inhibitor from Pfizer (PF-06263276) (Jones et al., 2017 ) is in preclinical studies by inhaled route for inflammatory diseases of the lungs, but no inhaled compound has reached clinical studies yet.

The aim of this study has been to describe the in vitro and in vivo profile of LAS194046 by i.t. route. For comparison purposes, the JAK inhibitors ruxolitinib and tofacitinib were also tested in the in vitro assays. Obtained results show that LAS194046 administered by i.t. route reduces allergeninduced airway inflammation, late asthmatic response (LAR),

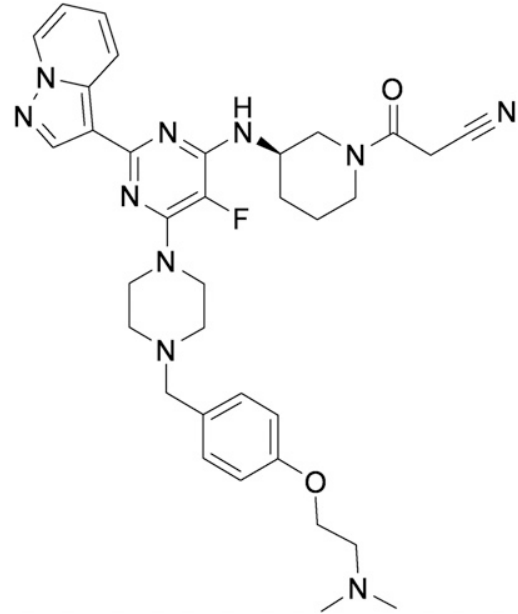

Fig. 1. Chemical structure of JAK inhibitor LAS194046.

and phosphor-STAT (pSTAT) activation in an ovalbumin (OVA)-challenged model in Brown Norway rats. Our data support the use of JAK inhibitors by inhaled route for the treatment of asthma.

\section{Materials and Methods}

Materials. The 3-((3R)-3-\{[6-(4-\{4-[2-(dimethylamino)ethoxy]benzyl\} piperazin-1-yl)-5-fluoro-2-pyrazolo[1,5-a]pyridin-3-ylpyrimidin-4-yl]amino\} piperidin-1-yl)-3-oxopropanenitrile (LAS194046) was synthesized at Almirall's Department of Medicinal Chemistry (Sant Feliu de Llobregat, Spain) (Fig. 1). Synthesis of LAS194046 is reported in patent application WO2015/086693. An article describing the work made in Almirall leading to the discovery of LAS194046 will be published in due course.

Ruxolitinib and tofacitinib were purchased from LC Laboratories (Woburn, MA) and MedChem Express (Monmouth Junction, NJ), respectively.

Animals. Male Sprague Dawley rats (250-300 g), male Wistar rats $(250 \mathrm{~g})$, and Brown Norway rats (150-170 g) were purchased from a commercial breeder (Charles River Laboratories, Barcelona, Spain) and housed at the animal facilities of Almirall throughout the study. They were housed in ventilated cages and kept in a room with controlled conditions of light (lights on from 07:00 to 19:00 hour, with 30 minutes of dawn and dusk), ventilation (15-20 air changes per hour), temperature $\left(22 \pm 2^{\circ} \mathrm{C}\right)$, and humidity $(55 \% \pm 10 \%)$. These conditions were maintained during a 5-day acclimation period. A standard rodent diet (2014 Teklad Global 14\% Protein Rodent Maintenance Diet; Envigo, Barcelona, Spain) and water were available ad libitum throughout the study. The care of animals was undertaken in compliance with the European Committee Directive 2010/63/EU and the Spanish and autonomous Catalan laws (Real Decreto 53/2013 and Decret 214/1997). Experimental procedures were reviewed by the Animal Welfare Body of Almirall and approved by the Generalitat de Catalunya as competent authority.

JAK Isoform Enzymatic Assay. The enzymatic activity of the different recombinant kinases, JAK1 (Life Technologies, Thermo Fisher Scientific, Waltham, MA), JAK2, JAK3, and TYK2 (Carna Biosciences, Kobe, Japan), was measured by homogeneous timeresolved fluorescence with ATP concentration fixed at the $K_{\mathrm{m}}$ for each JAK isoform.

Compounds were initially solubilized in DMSO at $1 \mathrm{mM}$ stock concentration, and dilutions were performed to finally reach $5 \%$ DMSO in the mixture of the substrates ATP (Sigma-Aldrich, Ayrshire, UK) and PolyGT-Biotin (Cisbio, Codolet, France) at a final concentration equivalent to their respective $K_{\mathrm{m}}$. The catalytic reaction was then 
started with the addition of the enzymes. The time of assay and enzyme concentration were optimized to work in the linear range. An EDTA solution was added to stop the reaction in combination with a mixture of streptavidin-XL665 and phosphotyrosine cryptate antibody (Cisbio) to detect the enzyme activity. The concentration of streptavidin-XL65 was optimized for each single kinase assay, whereas the concentration of the phosphotyrosine cryptate antibody was constant, as specified by the supplier. Final assay conditions are demonstrated in Table 1.

Sample reading was performed between 3 and 20 hours as signal remained stable. Dose-response curves and $\mathrm{IC}_{50}$ were obtained by using a four-parameter log equation according to model 204 in Excel fit software 2.3.

Cytotoxicity Assay. CHO-K1 cells (American Type Culture Collection, Manassas, VA) were seeded at a concentration of $10^{4}$ cells/well in 96 -well plate $(100 \mu \mathrm{l})$. Compounds were initially solubilized in DMSO at $10 \mathrm{mM}$ stock concentration, and dilutions were performed to finally reach $1 \%$ DMSO in F12 culture medium with $0.5 \%$ FBS for a 24-hour incubation of cells. The reduction of the ATP status of the cells was studied with ATPLite, a luminescence ATP detection assay system (PerkinElmer, Boston, MA), according to the manufacturer instructions, and luminescence was measured using a Luminoskan luminometer (Thermo Fisher Scientific). The inhibition of the ATP status for the different compounds was determined by using eight different concentrations that were run in duplicate. Dose-response curves and $\mathrm{IC}_{50}$ were obtained by using a four-parameter log equation according to model 204 in Excel fit software 2.3.

JAK Isoform Cellular Assays in Human Peripheral Blood Mononuclear Cells. Whole blood was obtained from consenting human volunteers (in accordance with the Spanish biomedical research law 14/2007, which complies with the Helsinki declaration). Peripheral blood mononuclear cells (PBMCs) were isolated in a Ficoll gradient, resuspended in RPMI 1640 medium, and seeded at a concentration of $3 \times 10^{5}$ cells/well in 96 -well plates $(95 \mu \mathrm{l})$. Compounds were initially dissolved in $100 \%$ DMSO and were diluted to reach a final concentration in cells of $0.5 \%$. Cells were preincubated with the test compounds for 30 minutes at $37^{\circ} \mathrm{C}$ and $5 \% \mathrm{CO}_{2}$ and then activated with the corresponding cytokine.

For IL-4/GM-CSF-induced pSTAT6 and pSTAT5 assay, cells were activated with $1 \mathrm{ng} / \mathrm{ml}$ IL- 4 and $0.015 \mathrm{ng} / \mathrm{ml}$ GM-CSF for 30 minutes. Then cells were fixed with Cytofix buffer (BD Biosciences, Erembodegem, Belgium) for 10 minutes at $37^{\circ} \mathrm{C}$, permeabilized for 30 minutes on ice, and stained with pSTAT6-Alexa 647 (pY641) and pSTAT5Alexa 488 (pY694) antibodies (612601 and 612588; BD Biosciences) for 30 minutes at room temperature.

For IFN $\alpha$-induced pSTAT1 and IL-12-induced pSTAT4 assays in human lymphocytes, cells were activated with $700 \mathrm{U} / \mathrm{ml} \mathrm{IFN} \alpha$ or with $6 \mathrm{ng} / \mathrm{ml}$ IL-12 for 30 minutes. Then cells were fixed with Cytofix buffer for 10 minutes, permeabilized for 30 minutes on ice, and stained with pSTAT1-Alexa 488 (pY701) antibody (612596; BD Biosciences) or with pSTAT4-Alexa 647 (pY693) antibody (558137; BD Biosciences) for 30 minutes at room temperature.

PBMCs were washed and resuspended in buffer for cytometric analysis in a FACSCalibur (BD Biosciences). Lymphocytes were identified by size and complexity in a forward light scatter/side light scatter plot, and monocytes were identified as CD33-positive cells (Fig. 2). In the case of lymphocytes, results were expressed as a change in median of fluorescence intensity for pSTAT1 or pSTAT4 or pSTAT6 and for monocytes for pSTAT5 or pSTAT6. IC $_{50}$ values were determined by nonlinear regression using XL-fit software for calculations.

IL-4-Induced pSTAT6 in Rat Monocytes. Whole blood was obtained from the abdominal aorta of Sprague Dawley rats. PBMCs were isolated in a Ficoll gradient, resuspended in RPMI 1640 medium, and seeded in a 96 -well plate $\left(5 \times 10^{5}\right.$ cells/well $)$. Cells were preincubated with the test compounds for 30 minutes at $37^{\circ} \mathrm{C}$ and $5 \%$ $\mathrm{CO}_{2}$ and activated with $1 \mathrm{ng} / \mathrm{ml} \mathrm{IL}-4$ for 20 minutes. Then cells were fixed with Cytofix buffer (BD Biosciences) for 10 minutes at $37^{\circ} \mathrm{C}$, permeabilized for 30 minutes on ice, and stained with pSTAT6-Alexa
TABLE 1

\begin{tabular}{lcccc}
\hline Enzyme & Reaction Time $(\mathrm{min})$ & Enzyme $(\mathrm{nM})^{a}$ & ATP $(\mu \mathrm{M})$ & polyGT $(\mathrm{nM})$ \\
\hline JAK1 & 30 & 7.5 & 3 & 60 \\
JAK2 & 30 & 2 & 0.2 & 30 \\
JAK3 & 30 & 0.3 & 0.6 & 140 \\
TYK2 & 15 & 10 & 1.75 & 50
\end{tabular}

${ }^{a}$ Enzyme concentration in the assay depends on enzyme batch.

647 (pY641) antibody (558242; BD Biosciences) for 30 minutes at room temperature. PBMCs were washed and resuspended in buffer for cytometric analysis in a FACSCalibur (BD Biosciences). Results were expressed as a change in median of fluorescence intensity for pSTAT6 in monocytes (HIS48 ${ }^{+}$cells). IC $_{50}$ values were determined by nonlinear regression using XL-fit software for calculations.

Selectivity Assays. Selectivity against 220 kinases was assessed at $10 \mu \mathrm{M}$ in different kinase panels (Millipore, Dundee, UK) by filtration, and results were expressed as percentage of inhibition of specific binding measured in the presence of the specific ligand (data not shown for all kinases). Assays were performed at the corresponding $K_{\mathrm{m}}$ of ATP for each enzyme. When significant inhibition (>80\%) was obtained for a particular target from these panels, studies to determine $\mathrm{IC}_{50}$ were performed. If required, subsequent studies to assess cellular inhibition were also considered.

Pharmacokinetic Study and Sample Analysis. Male Wistar rats weighing approximately $250 \mathrm{~g}$ were anesthetized with $4 \%$ isoflurane and placed in a supine position. Two hundred microliters of the test compound in solution $(0.38 \mathrm{mg} / \mathrm{ml})$, prepared in PBS with $0.2 \%$ Tween 80 and $2 \%$ DMSO (pH: 6), was administered directly into the trachea using a Liquid MicroSprayer (Penn-Century, Wyndmoor, PA). At predefined time points (0.01, 0.1, 1, 5, 22 hours), blood samples were collected and centrifuged to obtain blood plasma. Lungs were harvested after perfusion with saline through the right ventricle of the heart. Plasma samples were precipitated with acetonitrile and centrifuged, and the supernatant was analyzed by Liquid chromatography tandem-mass spectrometry (LC-MS/MS). Lungs were homogenized with methanol $(4: 1 ; \mathrm{w} / \mathrm{v})$ using an UltraTurrax (IKA-Werke, Staufen, Germany). The homogenates were then sonicated and centrifuged, and the supernatants were analyzed by LC-MS/MS. Chromatographic analyses were accomplished on a reversed-phase column (C18), followed by mass spectrometric detection in Multiple reaction monitoring (MRM) mode.

OVA-Induced Inflammation and LAR in Brown Norway Rats. Male Brown Norway rats weighing about $150-170 \mathrm{~g}$ on the sensitization date were i.p. sensitized on days 0,14 , and 21 with $100 \mu \mathrm{g}$ OVA (Sigma-Aldrich) and $20 \mathrm{mg}$ Imject Alum adjuvant (Thermo Fisher Scientific) in $1 \mathrm{ml}$ saline. On day 28, animals were i.t. treated with $0.2 \mathrm{ml}$ LAS194046 $(0.3$ and $1 \mathrm{mg} / \mathrm{kg}$ in $5 \%$ DMSO, $0.05 \% \mathrm{HCl} 1 \mathrm{~N}$ in PBS), vehicle (5\% DMSO, 0.05\% HCl $1 \mathrm{~N}$ in PBS), or fluticasone $(0.3 \mathrm{mg} / \mathrm{kg}$ in $0.2 \%$ Tween 80 in PBS) using a Microsprayer (Penn-Century). The effect of the vehicle used for fluticasone $(0.2 \%$ Tween 80 in PBS) was not tested in this study, as previous internal experience with this vehicle shows no effect in this model. After 1 hour, animals were challenged with $1 \%$ OVA or saline for 30 minutes administered by aerosol in an exposure chamber using a DeVilbiss UltraNeb Ultrasonic Nebulizer (DeVilbiss Healthcare International, Mannheim, Germany). Immediately after challenge, animals were placed in plethysmography chambers (Buxco Research Systems, Wantage, UK) to record changes in Penh for 6 hours, as measurement of lung function changes. Twenty-four hours after the OVA challenge, animals were terminally anesthetized with a dose of $200 \mathrm{mg} / \mathrm{kg}$ sodium pentobarbital administered i.p., and lung and bronchoalveolar lavage fluid (BALF) samples were obtained. For BALF samples, the trachea was cannulated and the lungs were lavaged twice with $3 \mathrm{ml}$ PBS containing 5\% FBS to measure neutrophils, eosinophils, and erythrocytes with a hematology analyzer Sysmex XT-2000iV (Sysmex, Kobe, Japan). For target engagement studies, lung samples were 
A

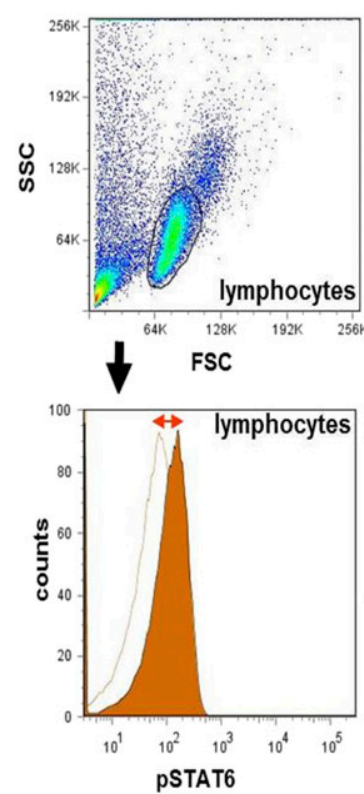

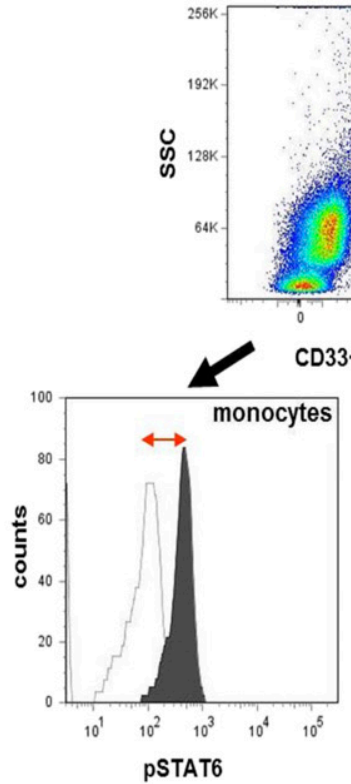

pSTAT6

\section{B}

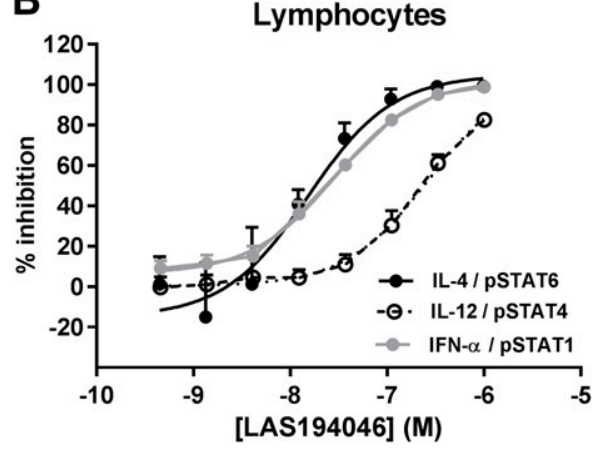

C

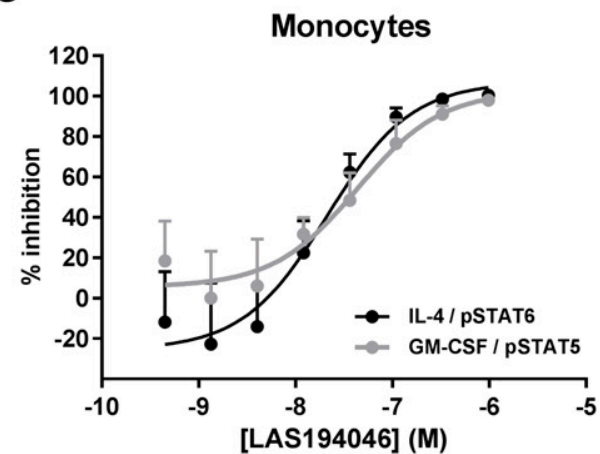

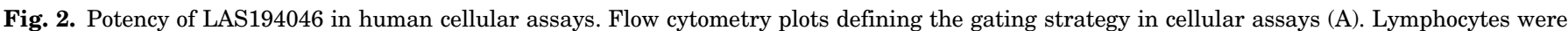

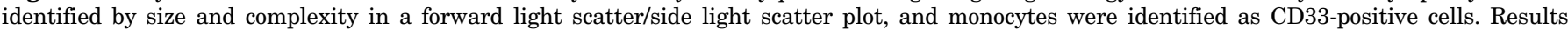

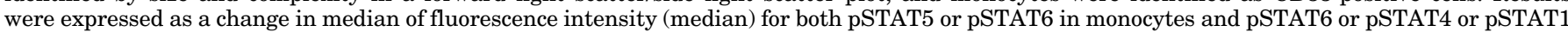

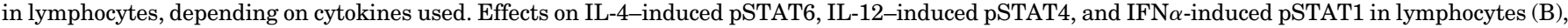

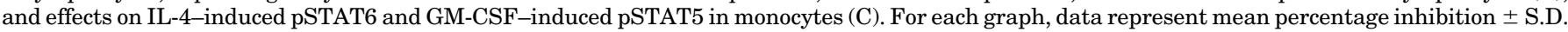
of two to three independent experiments run in duplicate.

obtained 1 hour after the OVA challenge. Data were expressed as mean \pm S.E.M.

Target Engagement Studies in Rat Lungs from the OVAInduced Airway Inflammation Model. Rat lung samples (the peripheral portion of the right caudal lobe) were obtained 1 hour after the OVA challenge and placed into a lysing matrix D tube with a 1.1-mm ceramic sphere (MP Biomedicals, Santa Ana, CA) and lysis buffer containing protease inhibitor cocktail set III (Merck Chemicals, Darmstadt, Germany). Samples were then homogenized using a FastPrep-24 homogenizer (MP Biomedicals) at $6 \mathrm{~ms}^{-1}$ for 20 seconds and two cycles.

pSTAT3 in tyrosine 705 was routinely analyzed in lung homogenates by ELISA following manufacturer instructions (STAT3, pY705, phosphoELISA Kit; Life Technologies, Alcobendas, Spain). Total STAT3 was measured by Luminex Technology following manufacturer instructions (MILLIPLEX MAP Total STAT3 MAPmate; Millipore, Molsheim, France).

Lung homogenates (40 $\mu \mathrm{g}$ protein) were run on a $7.5 \%$ SDS-PAGE (Bio-Rad, Hercules, CA) and then transferred to a $0.2-\mu \mathrm{m}$ nitrocellulose membrane. After blocking with $5 \%$ bovine serum albumin in Tris-buffered saline-Tween buffer, membranes were incubated with the primary antibody rabbit anti-phospho-STAT1 (Tyr701) at 1:2000 dilution (7649S; Cell Signaling, Danvers, MA) or anti-phospho-STAT6 (Tyr641) at 1:2000 dilution (11050; Signalway Antibody, College Park, MD) at $4^{\circ} \mathrm{C}$ overnight. Then the membranes were incubated with horseradish peroxidase-conjugated anti-immunoglobolin $\mathrm{G}$ at 1:20,000 dilution, detected by Luminata Forte Western horseradish peroxidase substrate (Millipore, Burlington, MA) and images acquired by the densitometry system Image Laboratory (Bio-Rad). To detect total STAT1 and total STAT6, membranes were stripped 10 minutes with Restore Western blot stripping buffer (Thermo Fisher Scientific) and reprobed following the method described above but using rabbit anti-STAT1 antibody at 1:2000 dilution (9172S; Cell Signaling) or mouse anti-STAT6 antibody at 1:1000 dilution (ab130235; Abcam, Cambridge, UK). Detection of housekeeping protein was also performed on the same membrane by using mouse anti- $\beta$-actin at 1 : 2000 dilution (8H10D10; Thermo Scientific Scientific) to confirm the same amount of proteins was loaded.

Analysis and quantification of Western blot images were done with the Image Laboratory software (Bio-Rad). To quantify the optical density for each band, the area under the curve was calculated. These data were used to calculate the ratios of pSTAT/total STAT and total STAT $/ \beta$-actin.

Statistical Analysis. In the in vivo experiments, comparisons between groups were done using a one-way ANOVA, followed by Dunnett's post hoc test using GraphPad Prism software (GraphPad Software, San Diego, CA). Differences were considered significant when $P<0.05$.

\section{Results}

Potency of LAS194046 in Enzymatic Assays for the Different JAK Isoforms. The enzymatic activity of LAS194046 (see structure in Fig. 1) was measured with homogeneous timeresolved fluorescence using the ATP concentration that corresponds to the $K_{\mathrm{m}}$ for each JAK isoform.

LAS194046 was a potent JAK1, JAK2, and JAK3 inhibitor with $\mathrm{IC}_{50}$ of $5.46,0.4$, and $2.07 \mathrm{nM}$, respectively, and less potent in TYK2 activity assay with an $\mathrm{IC}_{50}$ of $21.8 \mathrm{nM}$. For comparison, ruxolitinib behaved as LAS194046 in JAK1, JAK2, and JAK3, but was more potent in TYK2, and tofacitinib was less potent in JAK1, JAK2, and TYK2 than LAS146046 (Table 2). 
TABLE 2

Potency of LAS194046, ruxolitinib, and tofacitinib in biochemical activity assays for the different JAK isoforms

Potency for JAK inhibitors was measured by homogeneous time-resolved fluorescence with ATP concentration fixed at the $K_{\mathrm{m}}$ for each JAK isoform. Values expressed as the geometric mean (geometric S.D.) of at least three experiments performed in duplicate of each tested compound.

\begin{tabular}{lrcrr}
\hline & \multicolumn{4}{c}{$\mathrm{IC}_{50}(\mathrm{nM})$} \\
\cline { 2 - 5 } & \multicolumn{1}{c}{ JAK1 } & \multicolumn{1}{c}{ JAK2 } & \multicolumn{1}{c}{ JAK3 } & \multicolumn{1}{c}{ TYK2 } \\
\hline LAS194046 & $5.46(1.02)$ & $0.40(1.24)$ & $2.07(1.05)$ & $21.80(1.19)$ \\
Ruxolitinib & $3.83(1.09)$ & $0.17(1.00)$ & $6.60(1.15)$ & $1.80(1.37)$ \\
Tofacitinib & $16.20(1.03)$ & $1.47(1.14)$ & $1.73(1.00)$ & $245(1.26)$ \\
\hline
\end{tabular}

Potency of LAS194046 in Human Cellular Assays. To evaluate LAS194046 cellular inhibition of JAK isoforms in human primary cells, several assays based on dual phosphorylation in human PBMCs were established, as described in Materials and Methods. Flow cytometric analysis was performed to measure IL-4-induced pSTAT6 in lymphocytes and monocytes (JAK1/JAK3 activity) and GM-CSF-induced pSTAT5 in monocytes (JAK2/JAK2 activity). Lymphocytes were identified by size and complexity in a forward light scatter/side light scatter plot, and monocytes were identified as CD33-positive cells (Fig. 2A). The results of this study showed that LAS194046 is effective at blocking cytokine signaling depending on JAK1/JAK3, both in lymphocytes and monocytes (Fig. 2, B and C), and JAK2/JAK2 in monocytes with $\mathrm{IC}_{50}$ of 16,26 , and $37 \mathrm{nM}$, respectively (Table 3 ). Ruxolitinib showed similar potency as LAS194046, and tofacitinib was less potent at inhibiting cellular JAK2/JAK2 activity with an $\mathrm{IC}_{50}$ of $200 \mathrm{nM}$.

IFN $\alpha$ stimulation activates JAK1/TYK2 and results in the phosphorylation of STAT1. To measure the inhibitory activity of LAS194046 on JAK1/TYK2 signaling, a cellular assay based on flow cytometry analysis was established in PBMCs to measure inhibition of IFN $\alpha$-induced pSTAT1 in lymphocytes (Fig. 2B). The results of this study showed that LAS194046 is effective at blocking this signaling that depends on JAK1/TYK2 with a potency of $24 \mathrm{nM}$. Ruxolitinib and tofacitinib showed similar potency as LAS194046 with $\mathrm{IC}_{50}$ of 11 and $52 \mathrm{nM}$, respectively (Table 3 ).

To further characterize the cellular JAK isoforms inhibited by LAS194046, an assay dependent on JAK2/TYK2 signaling was established also in PBMCs stimulating with IL-12 and measuring the phosphorylation of STAT4 in lymphocytes also by flow cytometry (Fig. 2B). This study showed that LAS194046 blocks this signaling, with an $\mathrm{IC}_{50}$ of $220 \mathrm{nM}$ being more potent than tofacitinib with an $\mathrm{IC}_{50}$ of $1445 \mathrm{nM}$ and less potent than ruxolitinib with an $\mathrm{IC}_{50}$ of $35 \mathrm{nM}$ (Table 3).

As a whole, the results obtained in the different cellular assays suggest that LAS194046 is a pan-JAK inhibitor that blocks JAK1/3-, JAK1/TYK2-, and JAK2/JAK2-dependent cellular assays with similar potency and that is less potent in the TYK2/JAK2 cellular assay (Fig. 2; Table 3).

To establish the potency in a rat cellular assay, LAS194046 was also tested in rat PBMCs stimulated with IL-4 to measure pSTAT6. Interestingly, LAS194046 showed very similar potency at inhibiting pSTAT6 in rat cells with an $\mathrm{IC}_{50}$ of $15 \mathrm{nM}$, demonstrating a good cellular activity translation between human and rat species and thus supporting its evaluation in the rat efficacy model.

Selectivity against Kinases and Cytotoxicity. The selectivity of LAS194046 was tested against a panel of $220 \mathrm{ki}-$ nases. Eighty-two percent of the tested kinases showed less than $80 \%$ inhibition at $10 \mu \mathrm{M}$. Figure 3 shows a representative panel of 38 kinases biased toward those kinases with frequent cross-reactivity with JAK inhibitors. JAK1 was included as positive control. Twelve kinases of this panel, including Abl, Fgr, Flt1, Flt3, Flt4, Fms, Fyn, Lck, Lyn, Ret, Trk A, and Yes, were inhibited more than $80 \%$ by LAS194046 at $10 \mu \mathrm{M}$. For these kinases the enzymatic $\mathrm{IC}_{50}$ was determined showing values above $100 \mathrm{nM}$, except for Flt3 and Trk A, with values of 9 and $12 \mathrm{nM}$, respectively. For these last two kinases, the $\mathrm{IC}_{50}$ for LAS194046 was determined in cellular assays showing values of $190 \mathrm{nM}$ for Flt3 and $590 \mathrm{nM}$ for Trk A.

To ensure that compound was not cytotoxic, cell viability was measured in CHO-K1 cells by using the ATP-lite assay (measurement of intracellular ATP levels). Results obtained after 24 hours of compound incubation showed that LAS194046 had poor cytotoxic effect with an $\mathrm{IC}_{50}$ of $45 \mu \mathrm{M}$, much above the concentrations tested in the different cellular assays (approximately 200- to 2800-fold). Tofacitinib and ruxolitinib also showed a minor effect in this assay with $12 \%$ and $23 \%$ inhibition of cell viability at $100 \mu \mathrm{M}$, respectively.

Pharmacokinetic Profile of LAS194046. The pharmacokinetic (PK) profile of LAS194046 was evaluated in Wistar rat after single i.t. administration before performing in vivo efficacy studies. The lung concentrations decreased slowly over time with $2 \%$ of compound in the lung at the time point of 24 hours and a lung half-life of 11.4 hours. Plasma exposure was very low, with half-life in plasma of 8.4 hours. Free tissue levels in the lung were above the $\mathrm{IC}_{80}$ of the rat cellular assay at the moment of the challenge (Fig. 4; Table 4). The lung/plasma partitioning was 3500 , and the lung bioavailability after i.t. administration was very high (73\%). As a whole, LAS194046 had an excellent prolife for the inhaled route and could be evaluated in the OVA model in rat by the i.t. route.

Effects of Inhaled LAS194046 in the OVA-Induced Inflammation and LAR in Brown Norway Rats. Considering the promising results obtained with LAS194046 in in vitro studies and the sustained lung levels observed in the rat $\mathrm{PK}$, the model of OVA-induced inflammation and LAR was

TABLE 3

Potency of LAS194046, ruxolitinib, and tofacitinib in human cellular assays for the different JAK isoform pairs

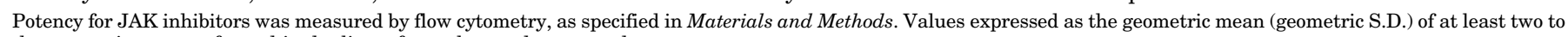
three experiments performed in duplicate for each tested compound.

\begin{tabular}{|c|c|c|c|c|c|}
\hline & \multicolumn{3}{|c|}{ Human Lymphocytes, $\mathrm{IC}_{50}(\mathrm{nM})$} & \multicolumn{2}{|c|}{ Human Monocytes, $\mathrm{IC}_{50}(\mathrm{nM})$} \\
\hline & IL-4/pSTAT6 (JAK1/3) & IFN $\alpha /$ pSTAT1 (JAK1TYK2) & IL-12/pSTAT4 (TYK2/JAK2) & IL-4/pSTAT6 (JAK1/3) & GM-CSF/pSTAT5 (JAK2/2) \\
\hline LAS194046 & $16(1.03)$ & $24(1.01)$ & $220(1.06)$ & $26(1.02)$ & $37(1.33)$ \\
\hline Ruxolitinib & $17(1.18)$ & $11(1.54)$ & $35(3.01)$ & $16(1.44)$ & $27(1.26)$ \\
\hline Tofacitinib & $23(1.27)$ & $52(1.68)$ & 1445 (1.67) & $36(1.35)$ & $200(1.44)$ \\
\hline
\end{tabular}




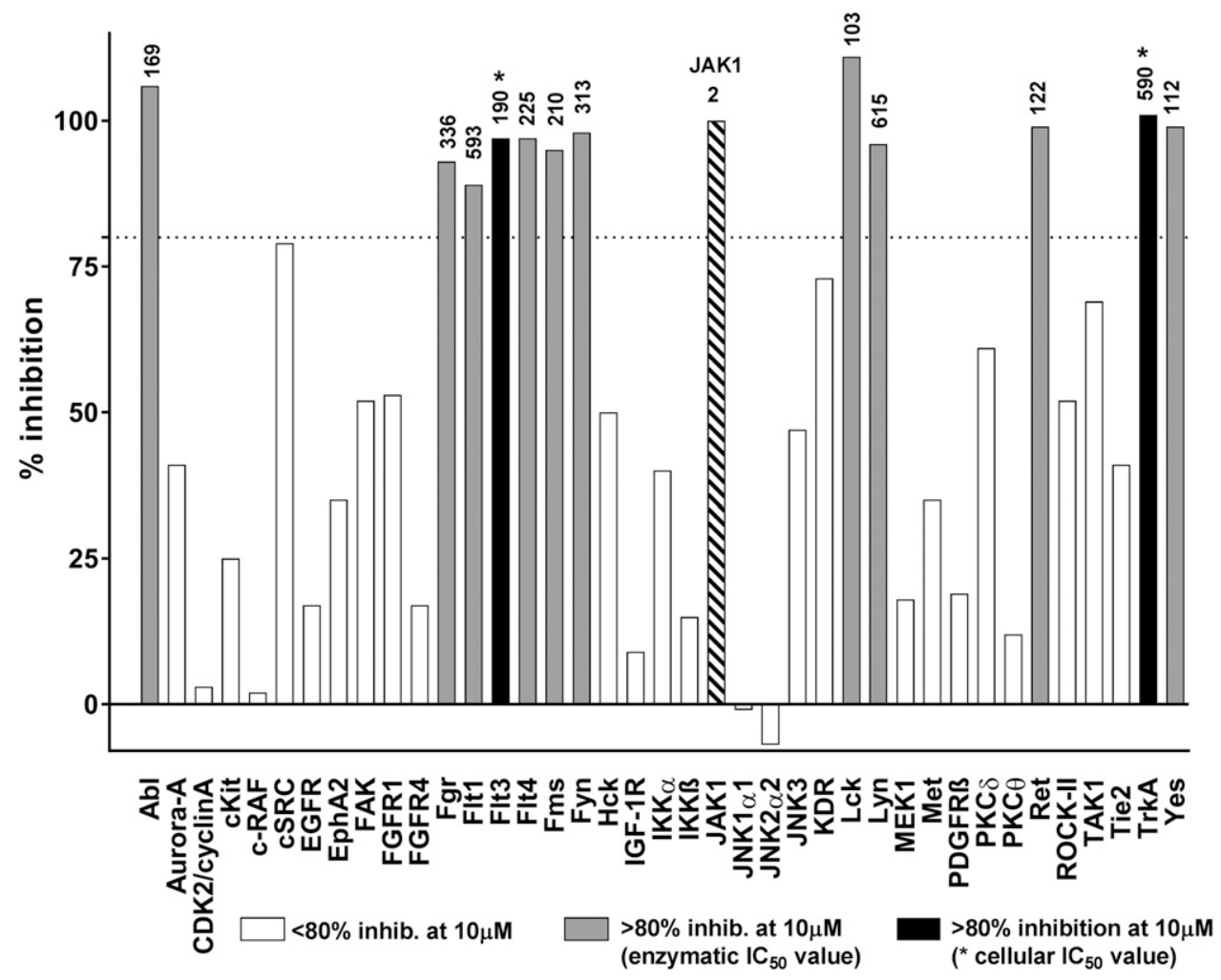

Fig. 3. Selectivity of LAS194046 against a panel of 38 kinases biased toward those kinases with frequent cross-reactivity with JAK inhibitors. Values represent percentage inhibition at $10 \mu \mathrm{M}$ (mean of two replicates) performed at the $K_{\mathrm{m}}$ of ATP. Enzymes showing inhibition below $80 \%$ at $10 \mu \mathrm{M}$ are represented with white bars. Enzymes showing inhibition above $80 \%$ and $\mathrm{IC}_{50}$ above $100 \mathrm{nM}$ in the enzymatic assay are represented with gray bars, and the $\mathrm{IC}_{50}$ values are indicated on top of the bar. Flt3 and TrkA are represented with black bars, and the cellular $\mathrm{IC}_{50}$ values are indicated on top of the bar. JAK1 activity was used as internal control in the enzymatic assays and represented with black and white bar.

selected to assess the in vivo efficacy. In this model, OVA challenge in sensitized rats causes an allergic inflammatory response that includes influx of inflammatory cells to the airways of the animals and functional lung changes that mimic certain features of human asthma (see Fig. 5, comparison between vehicle + saline and vehicle + OVA-vehicle groups). Administration of LAS194046 at $1 \mathrm{mg} / \mathrm{kg}$, i.t. 1 hour before OVA aerosol challenge, caused an inhibition of eosinophil and neutrophil infiltration in BALF of $64 \%$ and $63 \%$, respectively (Fig. 5A). Results obtained at $0.3 \mathrm{mg} / \mathrm{kg}$ did not show significant inhibition. Fluticasone at $0.3 \mathrm{mg} / \mathrm{kg}$, used as positive control, provided the expected result, causing an inhibition of neutrophil and eosinophil infiltration of $87 \%$ and $34 \%$, respectively.

In terms of lung function, OVA induced an increase in the late bronchoconstrictive response (LAR) measured as an increase in the Penh (Fig. 5B). LAS194046 significantly inhibited the LAR by $61 \%$ at the dose of $1 \mathrm{mg} / \mathrm{kg}$. At $0.3 \mathrm{mg} / \mathrm{kg}$ an inhibition of $10 \%$ was also observed, but without reaching statistical significance. As expected, positive control fluticasone inhibited the LAR in a significant way $(76 \%)$.

Target Engagement Studies in the Rat OVA Model by Measuring pSTAT1, pSTAT3, and pSTAT6 as Markers of JAK Signaling Pathway. Several studies were performed to assess the activation of the different pSTATs as potential target engagement markers for JAK inhibitors in the rat OVA model. Analysis of pSTAT3 in lung homogenates was performed by ELISA, and pSTAT1 and pSTAT6 were studied by Western blot. Initial internal studies showed that OVA induced a rapid phosphorylation of STAT1, 3, and 6 in lung homogenates, with an initial peak between 1 and 3 hours after OVA challenge (Fig. 6), with no relevant effect on total STATs, suggesting that 1 hour after OVA challenge was a suitable time point to assess the inhibitory effect of LAS194046 on the phosphorylation of these pSTATs in lung.

LAS194046 dose-dependently inhibited OVA-induced pSTAT3 in lung homogenates, reaching 50\% inhibition at the dose of $1 \mathrm{mg} / \mathrm{kg}$ with statistical significance. Fluticasone also significantly inhibited pSTAT3 phosphorylation at $0.3 \mathrm{mg} / \mathrm{kg}$ (Fig. 7C). In addition to pSTAT3, LAS194046 at $1 \mathrm{mg} / \mathrm{kg}$ i.t. almost completely inhibited pSTAT1 (79\%) and pSTAT6 (91\%), similarly to fluticasone (83\% and $104 \%$, respectively) (Fig. 7, A and B). Total STAT1, 3, and 6 protein expression was

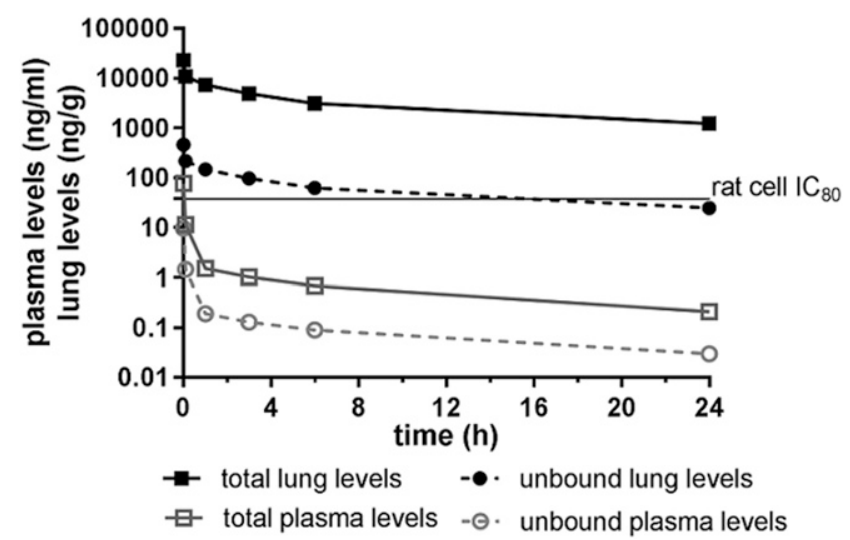

Fig. 4. Lung and plasma levels of LAS194046 after i.t. administration of $0.3 \mathrm{mg} / \mathrm{kg}$ by Liquid MicroSprayer. LAS194046 was prepared in $0.2 \%$ Tween 80 in PBS. Plasma samples and supernatants of lung homogenates were analyzed by LC-MS/MS. Data are represented as total and unbound levels. Unbound plasma levels calculated from rat Plasma protein binding (PPB) (87\%), and unbound lung levels calculated from lung tissue binding $(98 \%)$. Data represent the mean concentration \pm S.D. of three rats. 
TABLE 4

LAS194046 PK parameters in lung and plasma after administration of $0.3 \mathrm{mg} / \mathrm{kg}$ by i.t. route in Wistar rats

\begin{tabular}{lccccc}
\hline & $C_{\max }(\mu \mathrm{g} / \mathrm{g})(\mu \mathrm{g} / \mathrm{ml})$ & $C_{\min }(\mu \mathrm{g} / \mathrm{g})(\mu \mathrm{g} / \mathrm{ml})$ & AUC $(\mu \mathrm{g} \times \mathrm{h} / \mathrm{g})(\mu \mathrm{g} \times \mathrm{h} / \mathrm{ml})$ & $24-\mathrm{h}$ Dose Recovery $(\%)$ & $t_{1 / 2}(\mathrm{~h})$ \\
\hline Lung & 23 & 1.2 & 70 & 2 & 11.4 \\
Plasma & 0.077 & 0.001 & 0.02 & & 8.4 \\
\hline
\end{tabular}

AUC, area under the curve. Cmax, maximum concentration. Cmin, minimum concentration

not affected by the acute OVA treatment; changes were only observed in protein phosphorylation.

Considering that higher inhibition was observed for pSTAT6, a dose-response study was performed to explored the effect of lower doses of LAS194046 on STAT6 phosphorylation. LAS194046 dose-dependently inhibited OVA-induced pSTAT6 in lung homogenates, reaching the doses of 0.3 and $1 \mathrm{mg} / \mathrm{kg}$ (80\%) statistical significance. Fluticasone also significantly inhibited pSTAT6 expression at $0.3 \mathrm{mg} / \mathrm{kg}$ (Fig. 7D).

\section{Discussion}

The aim of this study was to generate evidences that JAKSTAT pathway inhibition by inhaled route constitutes a promising therapeutic option for lung inflammatory diseases such as asthma. We describe the profile of LAS194046, a novel inhaled JAK inhibitor, which reduces allergen-induced airway inflammation, LAR, and pSTAT activation in the rat OVA model by i.t. route.

Results obtained in our biochemical assays show that LAS194046 is a pan-JAK inhibitor, potent in JAK1-3 and less potent in TYK2. Compared with marketed JAK inhibitors, LAS194046 showed a similar profile to ruxolitinib but with lower potency in TYK2, whereas tofacitinib was less potent in JAK1, JAK2, and TYK2 isoforms.

Despite that tofacitinib was initially described as a selective JAK3 inhibitor with 20- and 100-fold less potency in JAK2 and JAK1, respectively (Changelian et al., 2003), the compound was later on reported as a pan-JAK inhibitor less potent in TYK2 (Jiang et al., 2008; Meyer et al., 2010; Yamaoka and Tanaka, 2014) in line with our results. Data obtained internally for ruxolitinib showed that the compound is a pan-JAK inhibitor potent also in TYK2. These data are somehow controversial with that published showing low enzymatic potency in JAK3 (Quintás-Cardama et al., 2010). Higher ATP concentration used in the published enzymatic studies compared with the internal assays performed with an ATP concentration equal to the enzyme $K_{m}$ could explain this discrepancy for JAK3.

Different assays were established internally to complete the JAK isoform inhibition profile at a cellular level. Obtained data suggest that LAS194046 inhibits JAK1/3 and JAK1/TYK2 assays in a similar range to both commercial compounds. Inhibition of JAK2/JAK2 was higher with our internal compound than with tofacitinib in agreement with data reported in the literature showing low potency in JAK2 for this compound (Meyer et al., 2010). Being more potent
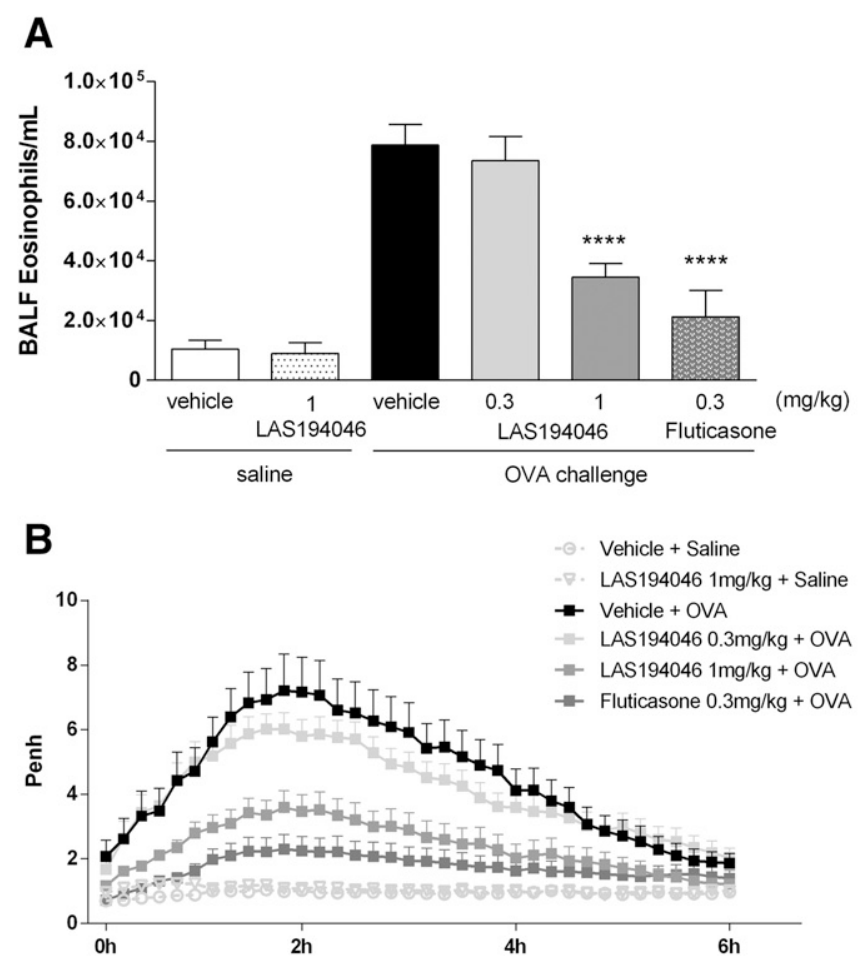
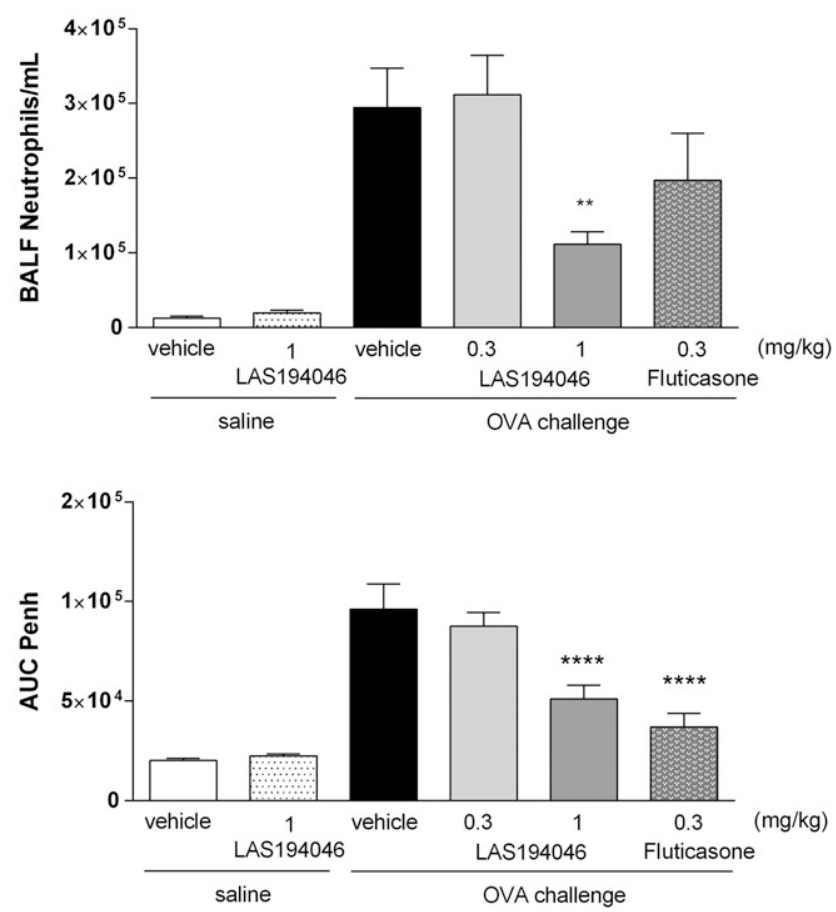

Fig. 5. Inhibition of inflammatory cell infiltration: eosinophils and neutrophils in BALF (A) and LAR, measured as Penh (B), induced by OVA challenge in a Brown Norway rat model after i.t. of LAS194046. Data represent mean \pm S.E.M. of three independent experiments, $n=21-24$. Statistical analysis was done using an ANOVA with a Dunnett's post hoc test. ${ }^{*}, * *, * * *, * * *: P<0.05,0.01,0.001$, and 0.0001 vs. vehicle + OVA group. 
A

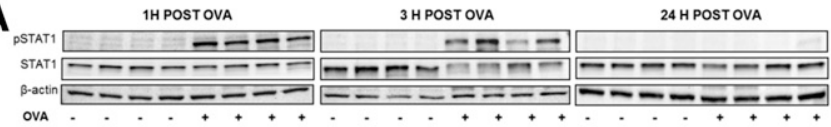

Ova
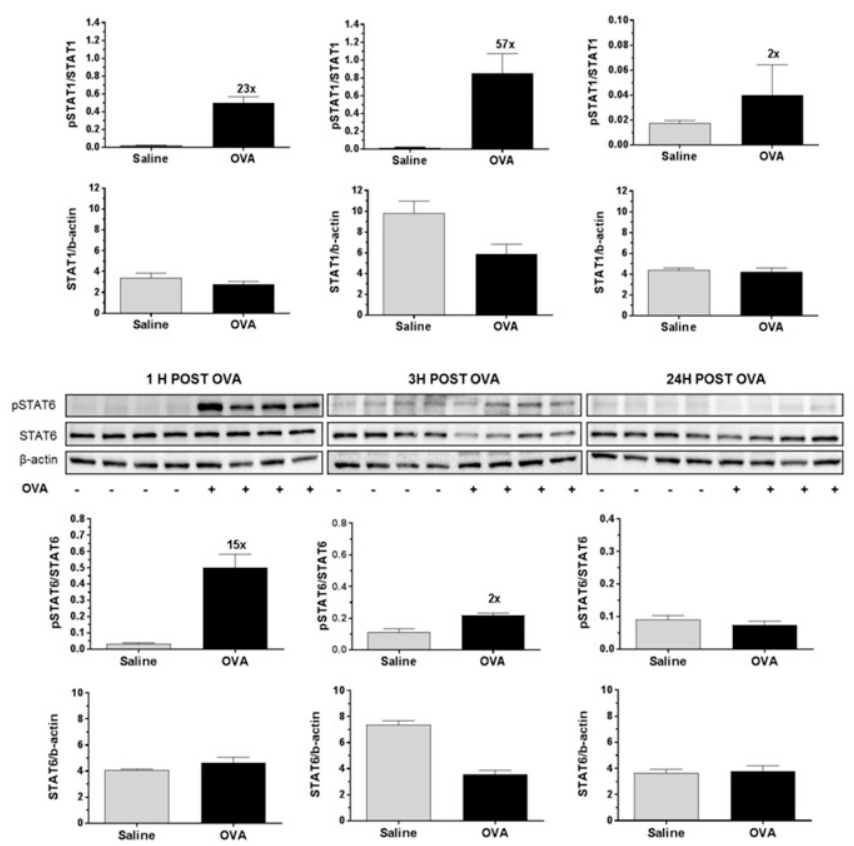

B
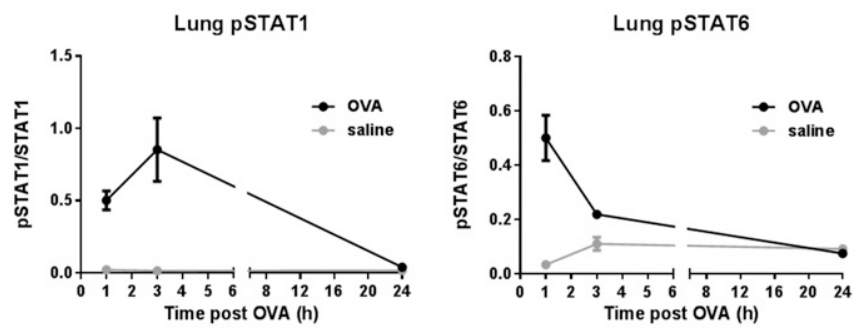

C
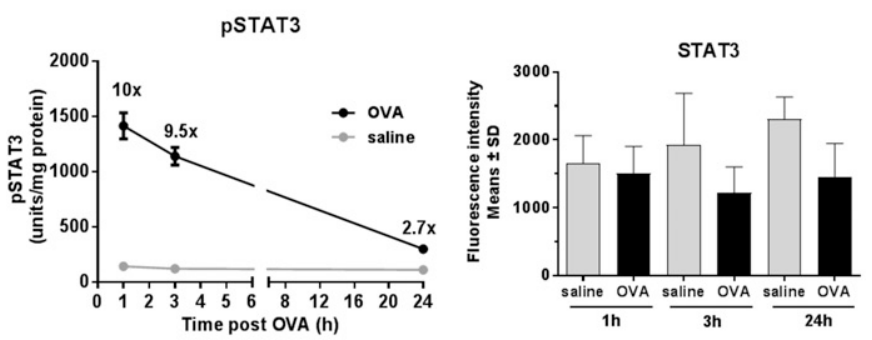

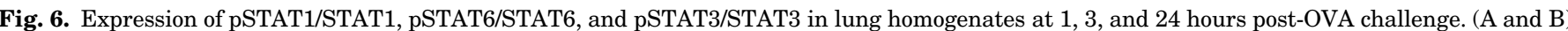

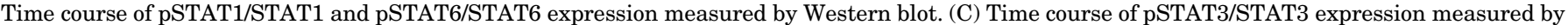
ELISA. Data shown as mean \pm S.E.M. $(n=8)$.

inhibiting cytokine receptors that associate and signal via pairs of JAK2 such as the IL-3, IL-5, and GM-CSF can add some benefit in terms of anti-inflammatory activity considering reduction of neutrophilia and eosinophilia, Th2 response, macrophage and mast cell activation, mucus production, and lung fibrosis (Milara et al., 2018). Also, JAK2 together with TYK2 and JAK1 associates with IL-13 receptors, causing the recruitment of STAT6. Polymorphisms of the latter are associated with asthma, atopy, and increased levels of IgE (O'Shea et al., 2015).

Other mediators such as erythropoietin and thrombopoietin signal also through JAK2, meaning that inhibiting JAK2 can be beneficial in terms of inflammation reduction, but can also have some negative effects such as thrombocytopenia, anemia, and hemoglobin reduction, as observed in clinical trial with oral tofacitinib at high doses (Park et al., 2013). This can be minimized by using inhaled JAK inhibitors that will avoid widespread systemic JAK inhibition while maintaining JAK inhibition in the lung, which is the target organ of interest in respiratory diseases. JAK2 also mediates IL-12 and IL-23 receptor signaling when associated with TYK-2, which has a relevant role in differentiation of naive $\mathrm{T}$ cells into Th1 and Th17, respectively (Minegishi et al., 2006). Th17 cells are associated with the more severe phenotypes of asthma as well as COPD (Newcomb and Peebles, 2013; Barnes, 2018), which are less responsive to corticosteroids and correlate with neutrophilic inflammation and frequent exacerbations, adding an extra benefit to JAK2 blockage in respiratory diseases. LAS194046 is more potent at inhibiting JAK2/TYK2 than tofacitinib, but less than ruxolitinib. Having a balanced inhibition of all JAK1-3 isoforms, but showing less potency on TYK2, also has some advantages in terms of adverse effects. TYK2-deficient mice show increased susceptibility to viral infections, which can be very relevant for an inhaled compound indicated for respiratory diseases such as asthma or COPD, in which microbial pathogens are the main cause of exacerbations (Karaghiosoff et al., 2000; Wark and Gibson, 2006; Celli and Barnes, 2007; Prchal-Murphy et al., 2012).

Considering the selectivity versus other kinases, LAS194046 did not show relevant off-target activities. Testing the compound against a panel of 220 kinases, including those kinases with frequent cross-reactivity with JAK inhibitors, revealed inhibition for Flt-3 and TrkA in enzymatic assays with $\mathrm{IC}_{50}$ at about $10 \mathrm{nM}$. However, potency obtained in cellular assays showed $\mathrm{IC}_{50}$ values well above the expected unbound systemic levels in a clinical setting. Unbound levels with a $C_{\max }$ at about $117 \mathrm{pM}$ were predicted using allometric scaling and simulation of levels in humans after inhaled administration, and, thus, no unexpected effects are anticipated. Tofacitinib appeared to be more selective than LAS194046 in a similar panel of 200 kinases, in agreement with data reported in the literature showing good selectivity for this compound (Karaman et al., 2008), whereas ruxolitinib was less selective than our internal compound (data not shown).

The design of optimal compounds for the treatment of respiratory diseases by inhaled delivery requires achievement of sustained effective lung levels while minimizing systemic exposure to reduce the potential risk of systemic adverse effects (Cooper et al., 2012). The affinity of inhaled drugs toward lung tissue is largely governed by their physicochemical properties, being basic and lipophilic compounds those that display pronounced lung retention due to nonspecific binding to cellular components (Tronde et al., 2003). The dibasic character of LAS194046 allows for high lung-plasma 
A

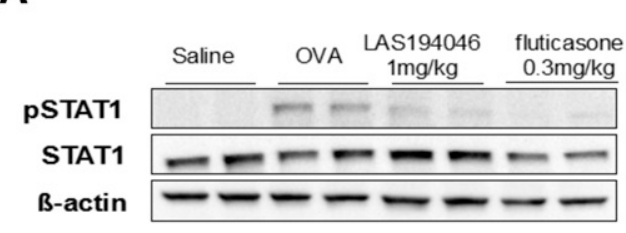

B
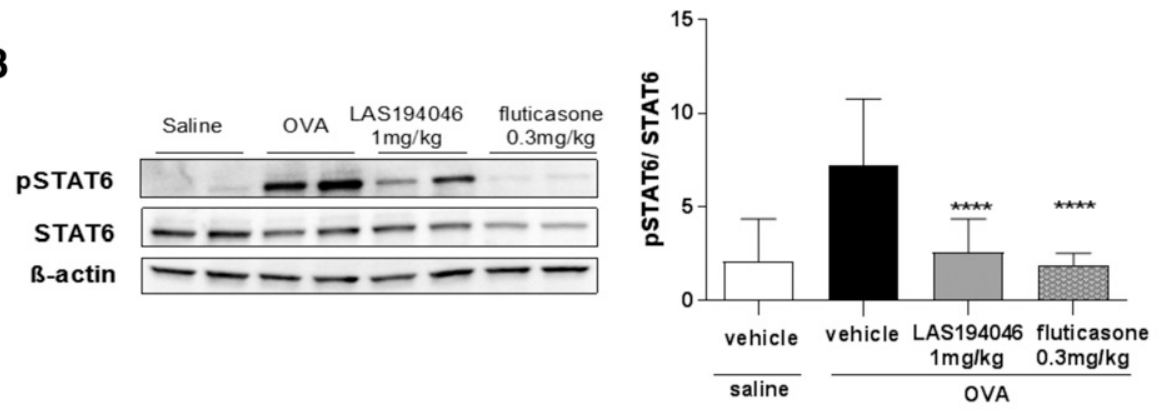
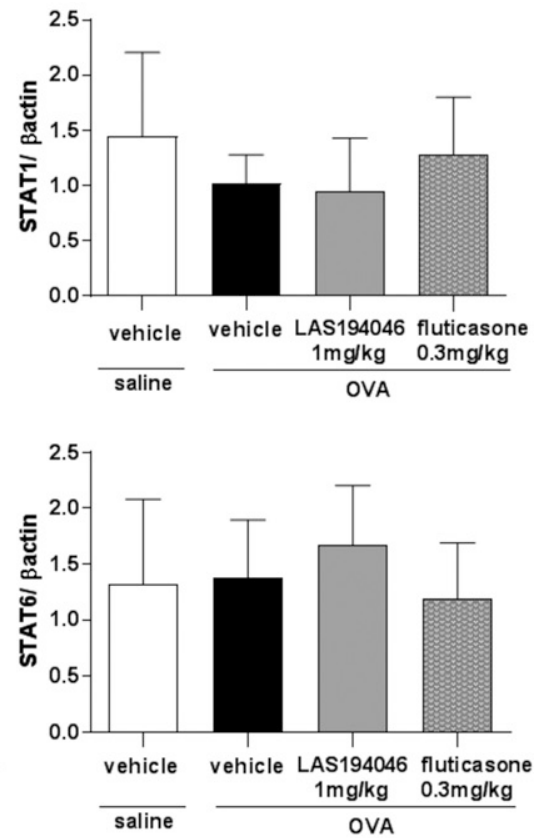

C

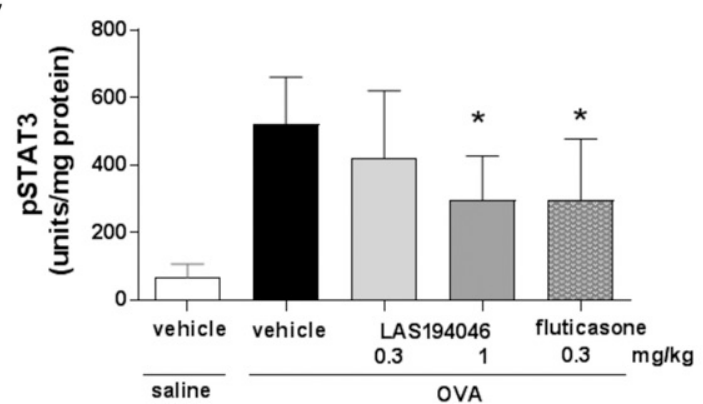

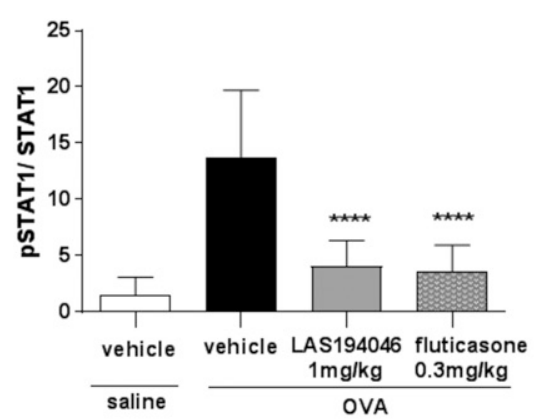

D

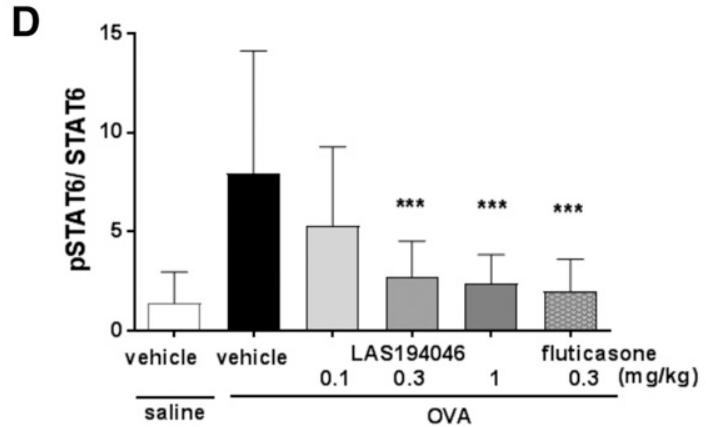

Fig. 7. Effect of LAS194046 after i.t. administration of 0.3 and $1 \mathrm{mg} / \mathrm{kg}$ on pSTAT1, pSTAT6, and pSTAT3 expression in lung homogenates postOVA challenge. Fluticasone $0.3 \mathrm{mg} / \mathrm{kg}$ i.t. was used as positive control. (A) pSTAT1. (B) pSTAT6. Representative Western blot analysis of pSTAT1-6, STAT1-6, and $\beta$-actin as a loading control (left). Densitometric analysis of pSTAT1-6/STAT1-6 expression (middle). Densitometric analysis of STAT1-6 corrected by $\beta$-actin for all groups (right). (C) pSTAT3 expression measured by ELISA. (D) Dose response of pSTAT6 expression measured by Western blot. Data shown as mean \pm S.E.M. $(n=8)$. Statistical analysis was done using an ANOVA with a Dunnett's post hoc test. *,**, ***, ****: $P<0.05,0.01,0.001$, and 0.0001 vs. vehicle + OVA group.

partitioning and very low free systemic plasma levels. The observed high lung retention of the compound after i.t. administration in rat renders LAS194046 suitable for inhaled administration in the efficacy model.

Although oral compounds such as tofacitinib, R256, and ruxolitinib have shown efficacy, reducing lung inflammation in different murine OVA models by oral route at doses of 15 , 25-50, and $180 \mathrm{mg} / \mathrm{kg}$, respectively (Kudlacz et al., 2008; Ashino et al., 2014; Li and Wang, 2018), LAS194046 was efficacious by inhaled route. LAS194046 inhibited eosinophil and neutrophil infiltration in BALF and LAR when dosed i.t. at $1 \mathrm{mg} / \mathrm{kg} 1$ hour before the OVA challenge. Integrating the results obtained in the rat cellular assay and the favorable rat $\mathrm{PKs}$ after i.t. administration, we can rationalize that in vivo efficacy results are consistent with unbound lung levels clearly above the cellular $\mathrm{IC}_{80}$ during the challenge phase and free plasma levels below the cellular $\mathrm{IC}_{80}$ in rat monocytes. Recognizing that there are limitations to such extrapolations, as a whole we believe that these results indicate that the in vivo efficacy of LAS194046 is due to local JAK inhibition in the lung.
JAK inhibitor from Pfizer, PF-06263276, has reported efficacy by i.t. route in a mice pharmacodynamic model of IL-6-induced pSTAT3 response in the lungs, mediated via the JAK1/JAK2 mechanism (Jones et al., 2017). By comparing lung pSTAT3 inhibition with systemic pSTAT5 inhibition following i.t administration of PF-06263276, they demonstrated that JAK inhibition in the lung was accountable for the observed in vivo activity (Jones et al., 2017).

To further prove local inhibition of the JAK/STAT pathway with LAS194046, target engagement studies were performed in the rat in vivo OVA model exploring lung activation of pSTAT3 by ELISA, and pSTAT1 and pSTAT 6 by Western blot in lung homogenates. LAS194046 at $1 \mathrm{mg} / \mathrm{kg}$ by i.t. route inhibited the phosphorylation of the three mentioned STATs showing a more potent effect on pSTAT1 and pSTAT6 than pSTAT3. Dose-response studies to explore the effect of lower doses of LAS194046 on pSTAT6 showed that 0.3 and $1 \mathrm{mg} / \mathrm{kg}$ had similar significant effects. Increase of several pSTATs has been reported in the literature in human airway of patients with asthma and COPD (Christodoulopoulos et al., 2001; Mullings et al., 2001; Yew-Booth et al., 2015), proving relevance 
of the JAK-STAT pathway in those diseases and the potential for these proteins to be used as target engagement markers in clinical studies (Southworth et al., 2018).

The preclinical data reported in this study show that LAS194046 is a pan-JAK inhibitor with an optimal profile in terms of enzymatic and cellular potency, off-target selectivity, and lung retention. By inhaled administration, LAS194046 reduces allergen-induced airway inflammation and LAR through inhibiting STAT1, 3, and 6 phosphorylation. The in vivo efficacy of LAS194046 is achieved in the absence of pharmacologically relevant systemic plasma levels, supporting the use of inhaled JAK inhibitors as a novel treatment of inflammatory airway diseases such as asthma, decreasing chances of potential adverse effects related with systemic treatment.

\section{Acknowledgments}

We acknowledge the excellent technical support of Encarna Jimenez, Julia Diaz, and Silvia Petit for the in vitro studies; Felix Gil and Isabel Pagan for OVA measurements; Laura Estrella for PK studies; and Gloria Aniorte for histology studies (Almirall).

\section{Authorship Contributions}

Participated in research design: Calama, De Alba, Miralpeix, Ramis, Calbet.

Conducted experiments: Carreño, Maldonado, Calaf, Calama,

Pauta, Bach.

Contributed new reagents or analytic tools: Maldonado, Orellana,

Calama, Bach.

Performed data analysis: Calama, Carreño, Orellana, Paris, Calaf.

Wrote or contributed to the writing of the manuscript: Calbet, Miralpeix.

\section{References}

Anonymous (2012) FDA approval of oral arthritis drug marks a first for Pfizer, news in brief. Nat Rev Drug Discov 11:895.

Ashino S, Takeda K, Li H, Taylor V, Joetham A, Pine PR, and Gelfand EW (2014) Janus kinase 1/3 signaling pathways are key initiators of TH2 differentiation and lung allergic responses. J Allergy Clin Immunol 133:1162-1174

Barnes PJ (2018) Targeting cytokines to treat asthma and chronic obstructive pulmonary disease. Nat Rev Immunol 18:454-466.

Calama E, Ramis I, Domènech A, Carreño C, De Alba J, Prats N, and Miralpeix M (2017) Tofacitinib ameliorates inflammation in a rat model of airway neutrophilia induced by inhaled LPS. Pulm Pharmacol Ther 43:60-67.

Celli BR and Barnes PJ (2007) Exacerbations of chronic obstructive pulmonary disease. Eur Respir J 29:1224-1238.

Changelian PS, Flanagan ME, Ball DJ, Kent CR, Magnuson KS, Martin WH, Rizzuti BJ, Sawyer PS, Perry BD, Brissette WH, et al. (2003) Prevention of organ allograft rejection by a specific Janus kinase 3 inhibitor. Science 302:875-878.

Christodoulopoulos P, Cameron L, Nakamura Y, Lemière C, Muro S, Dugas M, Boulet LP, Laviolette M, Olivenstein R, and Hamid Q (2001) TH2 cytokineassociated transcription factors in atopic and nonatopic asthma: evidence for differential signal transducer and activator of transcription 6 expression. J Allergy Clin Immunol 107:586-591.

Cooper AE, Ferguson D, and Grime K (2012) Optimisation of DMPK by the inhaled route: challenges and approaches. Curr Drug Metab 13:457-473.

Dymock BW, Yang EG, Chu-Farseeva Y, and Yao L (2014) Selective JAK inhibitors. Future Med Chem 6:1439-1471.

European Medicines Agency (2017) Olumiant ${ }^{\circledR}$ EPAR - product information.

Flanagan ME, Blumenkopf TA, Brissette WH, Brown MF, Casavant JM, Shang-Poa C, Doty JL, Elliott EA, Fisher MB, Hines M, et al. (2010) Discovery of CP-690,550 a potent and selective Janus kinase (JAK) inhibitor for the treatment of autoimmune diseases and organ transplant rejection. J Med Chem 53:8468-8484.

Geyer HL and Mesa RA (2014) Therapy for myeloproliferative neoplasms: when, which agent, and how?. Blood 124:3529-3537.

Guttman-Yassky E, Silverberg JI, Nemoto O, Forman SB, Wilke A, Prescilla R, de la Peña A, Nunes FP, Janes J, Gamalo M, et al. (2019) Baricitinib in adult patients with moderate-to-severe atopic dermatitis: a phase 2 parallel, double-blinded, randomized placebo-controlled multiple-dose study. J Am Acad Dermatol 80 913-921.e9.

Hsu L and Armstrong AW (2014) JAK inhibitors: treatment efficacy and safety profile in patients with psoriasis. J Immunol Res 2014:283617.

Jiang JK, Ghoreschi K, Deflorian F, Chen Z, Perreira M, Pesu M, Smith J, Nguyen DT, Liu EH, Leister W, et al. (2008) Examining the chirality, conformation and selective kinase inhibition of $3-((3 \mathrm{R}, 4 \mathrm{R})-4$-methyl-3-(methyl $(7 \mathrm{H}-$ pyrrolo[2,3-d]pyrimidin-4-yl)amino)piperidin-1-yl)-3-oxopropanenitrile (CP-690,550) J Med Chem 51:8012-8018.
Jones P, Storer RI, Sabnis YA, Wakenhut FM, Whitlock GA, England KS, Mukaiyama T, Dehnhardt CM, Coe JW, Kortum SW, et al (2017) Design and synthesis of a pan-Janus kinase inhibitor clinical candidate (PF-06263276) suitable for inhaled and topical delivery for the treatment of inflammatory diseases of the lungs and skin. J Med Chem 60:767-786.

Karaghiosoff M, Neubauer H, Lassnig C, Kovarik P, Schindler H, Pircher H, McCoy B, Bogdan C, Decker T, Brem G, et al. (2000) Partial impairment of cytokine responses in Tyk2-deficient mice. Immunity 13:549-560.

Karaman MW, Herrgard S, Treiber DK, Gallant P, Atteridge CE, Campbell BT, Chan KW, Ciceri P, Davis MI, Edeen PT, et al. (2008) A quantitative analysis of kinase inhibitor selectivity. Nat Biotechnol 26:127-132.

Kudlacz E, Conklyn M, Andresen C, Whitney-Pickett C, and Changelian $\mathrm{P}$ (2008) The JAK-3 inhibitor CP-690550 is a potent anti-inflammatory agent in a murine model of pulmonary eosinophilia. Eur $J$ Pharmacol 582: $154-161$

Li RF and Wang GF (2018) JAK/STAT5 signaling pathway inhibitor ruxolitinib reduces airway inflammation of neutrophilic asthma in mice model. Eur Rev Med Pharmacol Sci 22:835-843.

Mackay-Wiggan J, Jabbari A, Nguyen N, Cerise JE, Clark C, Ulerio G, Furniss M, Vaughan R, Christiano AM, and Clynes R (2016) Oral ruxolitinib induces hair regrowth in patients with moderate-to-severe alopecia areata. JCI Insight $\mathbf{1}$ : e89790.

Meyer DM, Jesson MI, Li X, Elrick MM, Funckes-Shippy CL, Warner JD, Gross CJ, Dowty ME, Ramaiah SK, Hirsch JL, et al. (2010) Anti-inflammatory activity and neutrophil reductions mediated by the JAK1/JAK3 inhibitor, CP-690,550, in rat adjuvant-induced arthritis. J Inflamm (Lond) 7: 41-52.

Milara J, Hernandez G, Ballester B, Morell A, Roger I, Montero P, Escrivá J, Lloris JM, Molina-Molina M, Morcillo E, et al. (2018) The JAK2 pathway is activated in idiopathic pulmonary fibrosis. Respir Res 19:24-35.

Minegishi Y Saito M, Morio T, Watanabe K, Agematsu K, Tsuchiya S, Takada $\mathrm{H}$ Hara T, Kawamura N, Ariga T, et al. (2006) Human tyrosine kinase 2 deficiency reveals its requisite roles in multiple cytokine signals involved in innate and acquired immunity. Immunity 25:745-755.

Mullings RE, Wilson SJ, Puddicombe SM, Lordan JL, Bucchieri F, Djukanović R, Howarth PH, Harper S, Holgate ST, and Davies DE (2001) Signal transducer and activator of transcription 6 (STAT-6) expression and function in asthmatic bronchial epithelium. J Allergy Clin Immunol 108:832-838.

Murray PJ (2007) The JAK-STAT signaling pathway: input and output integration. J Immunol 178:2623-2629.

Newcomb DC and Peebles RS Jr (2013) Th17-mediated inflammation in asthma. Curr Opin Immunol 25:755-760.

O'Shea JJ and Plenge R (2012) JAK and STAT signaling molecules in immunoregulation and immune-mediated disease. Immunity 36:542-550.

O'Shea JJ, Schwartz DM, Villarino AV, Gadina M, McInnes IB, and Laurence A (2015) The JAK-STAT pathway: impact on human disease and therapeutic intervention. Annu Rev Med 66:311-328.

Park SO, Wamsley HL, Bae K, Hu Z, Li X, Choe SW, Slayton WB, Oh SP, Wagner KU, and Sayeski PP (2013) Conditional deletion of Jak2 reveals an essential role in hematopoiesis throughout mouse ontogeny: implications for Jak2 inhibition in humans. PLoS One 8:e59675.

Ports WC, Khan S, Lan S, Lamba M, Bolduc C, Bissonnette R, and Papp K (2013) A randomized phase 2a efficacy and safety trial of the topical Janus kinase inhibitor tofacitinib in the treatment of chronic plaque psoriasis. $\mathrm{Br} J$ Dermatol 169 137-145.

Prchal-Murphy M, Semper C, Lassnig C, Wallner B, Gausterer C, TeppnerKlymiuk I, Kobolak J, Müller S, Kolbe T, Karaghiosoff M, et al. (2012) TYK2 kinase activity is required for functional type I interferon responses in vivo. PLoS One 7:e39141.

Quintás-Cardama A, Vaddi K, Liu P, Manshouri T, Li J, Scherle PA, Caulder E, Wen X, Li Y, Waeltz P, et al. (2010) Preclinical characterization of the selective JAK1/2 inhibitor INCB018424: therapeutic implications for the treatment of myeloproliferative neoplasms. Blood 115:3109-3117.

Rothstein B, Joshipura D, Saraiya A, Abdat R, Ashkar H, Turkowski Y, Sheth V, Huang V, Au SC, Kachuk C, et al. (2017) Treatment of vitiligo with the topical Janus kinase inhibitor ruxolitinib. J Am Acad Dermatol $\mathbf{7 6}$ 1054-1060.e1.

Sandborn WJ, Ghosh S, Panes J, Vranic I, Su C, Rousell S, and Niezychowski W; Study A3921063 Investigators (2012) Tofacitinib, an oral Janus kinase inhibitor, in active ulcerative colitis. $N$ Engl J Med 367:616-624.

Shuai K (2006) Regulation of cytokine signaling pathways by PIAS proteins. Cell Res 16:196-202.

Southworth T, Mason S, Bell A, Ramis I, Calbet M, Domenech A, Prats N, Miralpeix M, and Singh D (2018) PI3K, p38 and JAK/STAT signalling in bronchial tissue from patients with asthma following allergen challenge. Biomark Res 6:14-21.

Southworth T, Plumb J, Gupta V, Pearson J, Ramis I, Lehner MD, Miralpeix M, and Singh D (2016) Anti-inflammatory potential of PI3K $\delta$ and JAK inhibitors in asthma patients. Respir Res 17:124-135.

Suzuki K, Nakajima H, Saito Y, Saito T, Leonard WJ, and Iwamoto I (2000) Janus kinase 3 (Jak3) is essential for common cytokine receptor $\gamma$ chain $(\gamma(\mathrm{c})$ )-dependent signaling: comparative analysis of $\gamma(\mathrm{c})$, Jak3, and $\gamma(\mathrm{c})$ and Jak3 double-deficient mice. Int Immunol 12:123-132.

Tronde A, Nordén B, Marchner $H$, Wendel AK, Lennernäs $H$, and Bengtsson UH (2003) Pulmonary absorption rate and bioavailability of drugs in vivo in rats: structure-absorption relationships and physicochemical profiling of inhaled drugs. J Pharm Sci 92:1216-1233.

Vuitton L, Koch S, and Peyrin-Biroulet L (2013) Janus kinase inhibition with tofacitinib: changing the face of inflammatory bowel disease treatment. Curr Drug Targets 14:1385-1391. 
Wallace DJ, Furie RA, Tanaka Y, Kalunian KC, Mosca M, Petri MA, Dörner T, Cardiel MH, Bruce IN, Gomez E, et al. (2018) Baricitinib for systemic lupus erythematosus: a double-blind, randomised, placebo-controlled, phase 2 trial. Lancet 392:222-231.

Wark PA and Gibson PG (2006) Asthma exacerbations. 3: pathogenesis. Thorax 61 909-915.

Winthrop KL (2017) The emerging safety profile of JAK inhibitors in rheumatic disease. Nat Rev Rheumatol 13:234-243.

Yamaoka K, Saharinen P, Pesu M, Holt VE III, Silvennoinen O, and O'Shea JJ (2004) The Janus kinases (Jaks). Genome Biol 5:253.
Yamaoka K and Tanaka Y (2014) Targeting the Janus kinases in rheumatoid arthritis: focus on tofacitinib. Expert Opin Pharmacother 15:103-113.

Yew-Booth L, Birrell MA, Lau MS, Baker K, Jones V, Kilty I, and Belvisi MG (2015) JAK-STAT pathway activation in COPD. Eur Respir J 46:843-845.

Address correspondence to: Dr. Marta Calbet, Almirall, R\&D Center, Laureà Miró 408-410, 08980 Sant Feliu de Llobregat, Barcelona, Spain. E-mail: marta.calbet@almirall.com 